\title{
Writing Literature Reviews for Survey Papers: A Guide for Emerging Scholars
}

\author{
Hala Kamal
}

\section{Introduction}

Academic discourse and writing are the core of academic publishing. Until recently, publishing research was an academic activity required mostly from scholars who have spent years doing research and writing about it mainly in their theses. Previous generations (including mine) were strictly discouraged from having their thesis-related research published prior to the reception of their postgraduate academic degrees. It is only in the past few years, especially in our particular context of Egyptian academia, that postgraduate students enrolled in $\mathrm{MA}$ and $\mathrm{PhD}$ programmes are required to publish work from their theses while still in progress. This has led many postgraduate students to start learning a new academic skill without having models to follow from the previous generations, and hence caused much confusion as to the format of this kind of writing and the need for them to compete for publication in specialized journals and among advanced academics. Very recently, the Cairo University Council has recommended a new thesis-track (that is currently optional) to write a thesis that is article-based rather than the traditional book-oriented format. This requires the students to compile a number of published articles into a thesis, rather than write a thesis out of which an article is derived. In both tracks, and at the MA and $\mathrm{PhD}$ levels, the postgraduate student is required to publish a research article derived from the thesis, or a survey paper based on the thesis literature review.

This article is not intended as a research article about academic discourse and scholarship, but is rather intended as a 'Guide' for young scholars helping them understand the forms of theses, and their concomitant publishing requirements. The focus here is on the publishable survey paper as a development of a literature review, which is now an initial and foundational stage in writing a thesis, a paper,

\footnotetext{
* Professor of English and Gender Studies, Department of English Language and Literature, Faculty of Arts, Cairo University.

Cairo Studies in English 2021(1): https://cse.journals.ekb.eg/
} 
or a scholarly academic piece of writing. This article is grounded in the current requirements for the publication of thesis-related work in Egyptian universities, while at the same time taking into consideration the requirements for publication according to international academic standards. This guide is divided into four main parts, framed by the introduction and conclusion. The first section explains the various shapes, forms, and formats of theses and dissertations. It, in turn, includes three parts which explore the established and innovative forms of the theses, with particular focus on the Cairo University two parallel forms, known as the Old Track and the New Track. The second section briefly explains the macrostructures of theses, with the aim of situating literature reviews as an essential component of a thesis or a research article. The third section is devoted to a discussion of literature reviews with particular emphasis on the reasons why they are so important to research, and the way to work on a scholarly literature review to be included in a thesis or additionally published as a survey paper. This section relies heavily on expert guidelines and suggestions, with application on an imaginary topic for a literature review. The last section addresses the issue of turning a literature review into a publishable survey paper, using the author's direct experience in that respect as a case in point.

As a Guide, this article relies on scholarly material about academic discourse in general, as well as on books about writing theses, and specifically on developing literature reviews and publishing them as papers. The author additionally invents an imaginary literature review topic which is analysed and developed in the light of the readings; as well as using a published survey paper as a case in point to explain the process of turning readings into a literature review that is publishable as a survey paper. It is worth noting here that this article is primarily conceived as a Guide for young researchers and emerging scholars. Yet it also tends to provide insights not only relevant to thesis-writing but to research in general.

\section{Thesis Types and Forms}

As a form of academic discourse and academic writing, there are several established forms that theses can take, including more traditional structures up till the more recent creative and alternative formats. Paltridge (2002) offered one of the most useful studies on writing theses, based on an analysis of theses and dissertations with particular focus on "the organization and structure of theses and dissertations" in theory and practice (127). This has been more extensively developed by Paltridge and Starfield (2007), offering a detailed explanation of the process of thesis and dissertation writing, and explaining the four main thesis 
formats. In a more recent book, Lorrie Blair (2016) builds on previous research and analysis of theses, where she identifies three established types in addition to innovative creative and alternative thesis forms. These explanations prove particularly insightful and useful for understanding the philosophy of theses and dissertations as reports on long-term research projects, especially in the humanities, arts, and social sciences, in addition to their specific relevance to the two prevalent forms of theses at Cairo University in general, and as related to the Faculty of Arts regulations in particular.

\section{Traditional Forms}

Brian Paltridge and Sue Starfield (2007) as well as Lorrie Blair (2016) agree on the existence of established forms of theses and dissertations. In their chapter on "The Overall Shape of Theses and Dissertations", Paltridge and Starfield identify the established forms in terms of "the traditional simple thesis", "the traditional complex thesis", and the "topic-based thesis" (2007, 66-81). The main difference between these three structures lies in the fact that while the traditional simple thesis reports on just one study/author/text/concept among others, the complex thesis includes more than one aspect, each presented in a separate chapter using its own sources, tools, and results. These two share the general methodological framework governing the whole thesis (theoretical background and methods). Although similar to the complex thesis, the topic-based structure clearly includes a number of topics, more likely to be organised around concepts/issues/methods rather than authors and texts. Blair, however, classifies these three forms together under the term "monograph" which she describes as a "standard thesis" which "is a single, book-like monograph" (2016, 1-2), structured around the typical components of any thesis or piece of academic research: introduction, literature review, methodology, analysis, and conclusion, also conventionally known by the acronym IMRAD (introduction, methodology, review of literature, analysis and discussion).

\section{Published-Research Theses}

The main purpose of academic research is the generation and dissemination of knowledge, where theses in particular are expected to contribute to the state of the art in their discipline. However, due to the several years it takes a doctoral thesis to be completed and published as a book, as well as the time needed for turning a thesis chapter into a publishable research article, unpublished research might lose its freshness and immediacy. Consequently, the value of the research is conditional to the immediacy of its publication, whereby "many programmes 
that traditionally required monograph theses are rethinking their practices to include theses by publication" (Blair 2016, 2). This led to the emergence of a new form of theses (mostly at the PhD level) where the thesis is structured around published papers and is described by Blair in the following terms:

The thesis by publication is a collection of related papers either accepted or submitted for publication in research journals. The papers are linked by theoretical or practical connections that frame the research. The thesis can contain any number of papers, but most thesis committees require between three and seven. It is expected that the papers will have been published in peer-reviewed journals, and that the candidate is the first author or the major contributor of ideas and experimental data. In some disciplines, the first chapter must be published, the second submitted for review, and the last in progress at the time of the oral defense. Other programs expect all chapters to have been published or accepted for publication. (2016, 2)

As shown above, there are a few crucial conditions for the thesis by publication form. First, the thesis has to be structured from the beginning along a number of related chapters. Second, the chapters should be governed by a general theoretical framework and methodological connections, that bring together theses chapters/papers. Third, the papers must be published or accepted for publication in peer-reviewed journals where the candidate is recognised as the first author. Fourth, the thesis in its entirety has to offer a contribution to knowledge in its area of specialisation that is recognised by the examining committee during the thesis defense. There remain some variations among universities as to the numbers of the required papers and their publication statuses. Yet, all in cases, for a published-research thesis to be accepted and the degree granted, "the papers must form a coherent document and be more that a group pf single published papers", which can be achieved through the introduction, conclusion and "rhetorical connections between the papers" (3). Along similar lines, there is the category of "professional doctorates" which are occasionally found in the fields in which research is closely connected to professional practice, where the thesis can take the form of a monograph or a series of published reports (Blair 2016, 4). 


\section{Innovative Types}

Blair charts two main forms of innovative thesis formats including art projects and creative writing. In the first case, the thesis is designed to comprise a work of art that is contextualised theoretically in the light of previous examples, critical approaches to the , as well as offering a critical commentary on the work through a description/analysis of the artistic creation process. Similarly, some universities have accepted literary works as $\mathrm{PhD}$ theses, such as novels. Such a thesis, however, does not comprise only of the literary text, but should be contextualised in a way to reveal a scholarly knowledge of the genre, its history, and its developments, as well as to offer a contribution as an artistic/literary creation. Blair clarifies that point stating that the novel/thesis for example should be based on intensive research and the product should reveal and add to knowledge in that genre/area, as those who "choose to write a novel must know their research well. Additionally, they must know the conventions of the novel form, and they must be able to write their research findings in that convention" $(2016,5)$. As interesting and innovative as these thesis formats are, their writers take the risk of facing employment difficulty, in addition to its often being "more challenging and more consuming" than the established thesis forms and types.

\section{Cairo University Tracks}

The Egyptian Supreme Council for Universities has for decades established the $\mathrm{PhD}$ thesis in the monograph form, in which the $\mathrm{PhD}$ student reports on her/his $\mathrm{PhD}$ research done over a long period of time. Since 2018, a PhD student has been required to provide evidence of publication of work derived from the thesis in scholarly peer-reviewed journals - either one paper internationally published, or two papers published in Egyptian journals in the student's area of specialization. This, however, did not affect the general reliance on the monograph form of the thesis itself. Added to this, the Faculty of Arts at Cairo University had developed, in its Bylaws (لائحة الدر اسات العليا), a fixed format of the components of a thesis-proposal as well of the thesis itself. Recently, in the light of the international changes in the postgraduate publishing culture, the Cairo University Council has introduced a "New Track" in PhD and MA thesis formats, emphasising the publication of the research prior to the submission of the thesis for examination. This enables students to select their preferred thesis track in agreement with their supervisors. Thus, the types approved by the Faculty of Arts, Cairo University and the Egyptian Supreme Council for 
Universities include the traditional simple and complex forms, as well as the topic-based and published-research theses.

Following the "Old Track" (المسار القديم), a student was expected to write a monograph thesis within a specific number of years after having the thesisproposal accepted, and the required paper(s) published, prior to the submission of the thesis for examination. According to the "New Track" (المسار الجديد) also known as the "Parallel Track" (المسار الموازي), valid as of the 1 st of October 2021, an MA and a $\mathrm{PhD}$ candidate, choosing this track, has to present a thesis proposal reflecting the new track in its structure. That is to say, the MA thesis includes two research articles, one of which can be a survey paper (based on the literature review); while at the $\mathrm{PhD}$ level, the thesis must include at least three research articles. These papers have to be inserted within the more conventional thesis structure, which necessarily includes the following components: the rationale, the aim and scope, the hypotheses, premises, and research questions, as well as the overall theoretical framework and methodology governing the whole thesis, and ends with a general conclusion and a comprehensive bibliography. Every paper, in turn, is governed by its own literature review, tools, methods, analysis, and results, which all fit within the over-arching thesis macro-structure.

\section{Macrostructures of Theses and Dissertations}

Any piece of publishable academic writing is expected to include the elements known as IMRAD; that is to say the Introduction, the Methodology, the Review of Literature, the actual Analysis, and finally the Discussion and Conclusion. These components are the core of the macrostructure of any research article or thesis, though they do not appear verbatim as chapter titles or section headers except in very traditional academic writing. Consequently, every thesis of every form and type includes these components (see e.g. Paltridge \& Starfield 2007; McMillan \& Weyers 2013; Blair 2016; Felix \& Smith 2019). The macrostructure can vary from one thesis form or type to another not in the existence of its components, but in their location within the thesis. So for example, a traditional thesis will follow the IMRAD macrostructure in its overall chapterisation, starting with an Introduction, followed by the Methodology, the Literature Review, the Analysis, and ending with Discussion and Conclusion, followed of course by the Bibliography. The complex, topic-based, publishedresearch types of theses all require the IMRAD components, but are more flexible about their locations within the theses. IMRAD can be over-arching, but the Analysis can be divided among several chapters/papers each with its own specific methods, sources (hence literature review), and conclusion. 
The literature review lies at the core of the macrostructure of any research article or thesis. It is the literature review that reveals the extend of the student's organised reading and acquired knowledge in the area of her/his research. It is through these readings (the literature review) that the research gap can be identified, the research questions formulated, and the methodology explained. It is, therefore, the only IMRAD component of a thesis that is publishable academically in the form of a Survey Paper. It is consequently crucial for emerging scholars to learn how to develop a comprehensive literature review of their research, and transform it into a publishable paper. This becomes of particular relevance to our current situation at Cairo University, where a New Track MA thesis can include a published literature review. Additionally, every publishable paper requires a literature review which forms the foundation of any valuable research project - which does not at all have to come under the traditional section heading "literature review", but can take a more creative form derived from the research field itself, reflecting the writer's efforts in classifying, organising, synthesising, and presenting her/his readings. This can take place, and has to take place, within any of the thesis formats discussed above.

\section{Literature Reviews: Why and How}

A literature review is the foundation of any research project, and as such has multiple functions in a paper or thesis. It presents the previous research done in the area of the thesis; it contextualises the current research within the wider frame of work done by others; it reveals the gap in research that the current paper or project is attempting to address; it suggests the rationale of the current research, its potential, and its expected contribution. In their chapter on "Writing the Background Chapters", Paltridge and Starfield draw a table of the steps and strategies used in writing a literature review, which they indicate in the following steps. A literature review starts before the process of writing, and it involves locating the required readings and offering a critical reading of the sources. The writing itself should begin with an outline followed by organizing it into sections and sub-sections. Finally, the literature review should lead to identifying the research gap, and hence formulating the research questions of the thesis/paper (2007, 104).

A more elaborate model is offered by Jose Galvan and Melisa Galvan (2017), who provide concrete guidelines to writing the literature review which include the following: 
Guideline 1: Look for Explicit Definitions of Key Terms in the Literature

Guideline 2: Look for Key Statistics to Use near the Beginning of Your Literature Review

Guideline 3: Pay Special Attention to Review Articles on Your Topic

Guideline 4: Make Note of Short but Important Quotations that Could Be Used Very Sparingly in Your Review

Guideline 5: Look for Methodological Strengths

Guideline 6: Look for Methodological Weaknesses

Guideline 7: Distinguish between Assertion and Evidence

Guideline 8: Identify the Major Trends or Patterns in the Results of

Previous Studies. (53-60)

These points cover the pre-writing process, whereby the researcher is still at the stage of reading, thinking, organizing and conceptualising the literature review in relevance to her/his research project. It is worth noting that in addition to collecting information and identifying potential quotations, writing a literature review involves a critical reading process, which takes into consideration methodological, discursive, as well as analytical features.

Similarly, in a chapter significantly entitled "Reading, Reading, Reading: Background to Your Literature Review", Mark Felix and Ian Smith explain the effects of extensive reading upon choosing a research/thesis topic which can be summarised in the following. It widens the perspective of the research; ensures the researcher's grounding and up to date knowledge; establishes the research gap; provides examples and enables comparisons; grants awareness of all the critical views related to the research topic; hence contextualising the current research and suggesting its contribution to the field (2019, 41-46). In another chapter, the authors point out that the literature review is not a section or chapter comprised of cutting and pasting from available sources, but is rather "an elegant piece of writing that supports with evidence and justifies the rationale of your research" and consequently requires "great amounts of thought, editing, revisions and strong references" (75). The authors give five concrete suggestions for the process of writing the literature review, listed below:

Suggestion \#1: Categorization of information 
Suggestion \# 2: Strive for continuity and connectivity between sections, subsections and paragraphs

Suggestion \#3: Be sure that the information that you have used in your Literature Review is based on/acts that are cited and referenced Suggestion \#4: Write brief summaries at the end of each section Suggestion \#5: Concluding the Literature Review. (Felix and Smith 2019, 78-80)

These suggestions emphasise a series of steps required for an acceptable literature review. The researcher must classify and categorise the readings, grouping them and setting them in sections. The connection needs to be clearly expressed so that the literature review relates the readings to each other and to the current research article/thesis. One of the most effective organizational means that also reveals the process of logical and critical thinking can be found in the way the readings are grouped either under headings, or through the logical flow of separate yet interconnected paragraphs. To avoid plagiarism and malpractice, all the sources have to be well integrated and clearly cited, whether directly quoted, paraphrased, summarised, or mentioned. Finally, the whole literature review must take the form of an academic essay, following its conventions, as well as having an introduction and conclusion.

\section{Example: Components of an Imaginary Literature Review}

If a paper or thesis project seeks to present an autobiographical reading of a selection of texts by different authors, the gap and the rationale can only be explained through the literature review which includes mapping the area of autobiographical theory as well as the critical work done on the selected authors and texts. That is to say that a thesis, for example, on "the autobiographical writing of Alice Walker", will be based on readings done on all the writings of Alice Walker, within the theoretical framework of autobiography theory, which will then lead to focusing on specific concepts related to genre and technique in the selected texts by this author. The choice of the topic itself is the outcome of initial reading and a hypothetical stance that Alice Walker has written autobiographical texts. In that sense, the literature review of a thesis topic (or research article) would necessarily be structured around three aspects, one leading to the other and complementing it within the framework of the thesis/paper. In this particular example (topic), the research and reading leading to a literature review will address initially three areas: Alice Walker's oeuvre, 
critical readings on Alice Walker's writings, and readings on autobiography theory.

Following Felix and Smith's suggestions, the process begins with extensive reading and organizing the reading material into an annotated bibliography of the research project, where sources are classified according to their relevance to different parts of the research project (data or texts, critical interventions, theoretical considerations). Within these broad categories, the researcher will have to create subcategories covering each of the texts, concepts, and terms. Once this initial stage of research is done, the researcher can move to the next step; namely working on the literature review, whereby she/he selects the most relevant sources to the research project, and begins rereading this sources with the purpose of producing a literature review. The overall thesis/paper review gives an overview of the research project as a whole, as well as its particular elements and aspects. So, in our particular example of the imaginary research topic on the autobiographical writing of Alice Walker, following the topic-based structure (the typical format used in the Old Track), the thesis/paper would include a literature review of the main sources governing the whole thesis inserted within the Introduction. Specific readings relevant to particular chapters of the thesis can be included in the introductions to their relevant chapters.

Now to stretch the example of the Alice Walker topic further, the thesis would include an Introduction that has sections presenting the main readings and sources on the texts analysed in the thesis, the major critical works on Alice Walker, and an explanation of the history and theory of autobiography in relation to the selected texts. Depending on the chapterisation of the thesis, the remaining sources will fit within their prospective chapters. So a chapter about Walker's autobiographies will focus on the term 'autobiography' in relation to other related concepts and terms such as 'memoir', and its application to the selected texts, in the light of critical work in that respect. Another chapter on Walker's collected essays would focus on autobiographical aspects of essays and the cross-generic connections and disconnections; while a chapter on her fiction would look at the autobiographical elements in her novels in the light of such terms as 'autobiographical novel' and perhaps 'autofiction'. Another thesis/paper could look at Alice Walker's work from a gender, class, and race perspective (rather than adopting a generic approach); while a third approach would look at Alice Walker's writings in the context of the history of slavery and racism in the USA; and a fourth could rely on theories of Marxist ecofeminism. And the list goes on! In each of these cases, every chapter could address one of these critical categories in relation to the selected texts. All of 
these choices of theoretical framing, methodological tools, terms, and concepts, or the notions of time, place, environment, society, and culture would form that methodology that requires explanation in its own right. It is, also, directed and conditioned by the readings and consequently the literature review, which grounds and frames the whole research project, and provides it with its raison d'être.

\section{From Literature Review to Survey Paper}

A literature review can remain merely a component of a thesis, but can also be transformed into a publishable paper. This has always been the case with Survey Papers, but has recently been widely encouraged by thesis supervisors, if not required by postgraduate institutions. A Survey Paper is less popular in academic publishing, and some journals even announce that they only accept original research and do not consider survey papers for potential publication. So for a researcher seeking to publish a literature review derived from her/his thesis, the best options would be to approach journals which accept survey papers, or look for special issues which address the specific area of her/his specialisation that might be interested in including a survey paper of the state of the art research in that field. Some journals occasionally approach specialists in certain areas inviting them to submit survey papers that would give an overview of certain disciplines, concepts, latest development or emerging trends in fields of knowledge. In this case, the researcher not only has to avoid plagiarism by upholding the ethics of accuracy and precision in referencing and citing, but has to be also careful not to fall into the trap of self-plagiarism. Once publishing is involved, the publishable paper cannot be directly extracted from the thesis, but rather requires a process of framing it as a survey paper that can stand on its own without being dependent on the thesis context.

In that respect, in their highly popular and repeatedly published book briefly mentioned above, entitled Writing Literature Reviews $\left(2017\right.$; this is the $7^{\text {th }}$ edition since its first edition in 1999), Jose Galvan and Melisa Galvan explain at length the process of writing literature reviews for publication. In their explanation of the nature of literature review articles they clarify the requirements for a publishable literature review:

Most journals that publish review articles set high standards for accepting such articles. Not only must they be well-written analytical narratives that bring readers up-to-date on what is known about a given topic, they must also provide fresh insights that advance 
knowledge. These insights may take many forms, including (a) resolving conflicts among studies that previously seemed to contradict each other, (b) identifying new ways to interpret research results on a topic, and (c) laying out a path for future research that has the potential to advance the field significantly. As a result, going through the process of preparing a literature review is not an easy way to get published in a journal. (7)

The challenging aspects of publishing literature reviews can be therefore identified in terms of providing a critical analysis and interpretations of the reviewed sources as well as contributing to knowledge and opening up vistas for further research projects. In that sense, a literature review is not just a summary of what exists but a conceptualisation of the field, opening new vistas and raising further questions for future research. A publishable literature review, in that sense, does not merely present the foundations of the current research project, but provides a survey of the state of the art, and a solid ground for further scholarship. It is worth noting, however, that a literature review article should have a title of its own. A paper entitled "A Literature Review of ..." is not at all likely to be accepted for publication, but should be phrased in a way to express its contribution to the field. Yet it should never pretend to be a research article, which should be indicated in the title of the paper as can be found in the case presented below.

\section{Case in Point: "Trends in Autobiography Theory and Writing"}

As mentioned above, some journals may ask a specialist to contribute an article or a book chapter that can be seen as a development of a literature review. It is usually termed as a survey paper, and in many cases can have the word 'Survey' in the title showing the genre, movement, theory, concept, method, approach, or whichever topic or aspect that is the subject of the Survey Paper. I wish in the following to focus on a case in point represented by my paper entitled "Trends in Autobiography Theory and Writing" (Kamal 2020), published in the Polish academic journal Philological Studies (available online open access). I am going to focus here on three dimensions: the title, the structure, and the academic metadiscourse used in the paper, highlighting the process of turning an unpublished literature review into a published article in the form of a survey paper. 
The Title. To begin from the beginning, the title of the paper indicates its nature. It does not carry the typical components of a research article, whether in the form of an implied research question, or with reference to the material, method, and/or theoretical framework - the three components of a publishable research article. Instead, this literature review turned survey paper states clearly in its title that it deals with one specific theory (autobiography theory) and the texts applying it (autobiographical writing). The contribution of the paper is implied in the word 'Trends' which suggests that the paper will provide a classified and categorised content. It is not just a list, nor a chronology, but it involves an analytical and critical effort. All of this is unequivocally expressed in the opening sentence of the Abstract which reads as follows: "This paper offers a survey of autobiography theory and writing in the Western tradition; and seeks to contribute to autobiography studies, by bringing together a variety of autobiographical writings and methods to present an over-reaching understanding of autobiography in theory and practice" (Kamal 2020, 179). This same point is reiterated in both the introduction and the conclusion of the paper, where the fact that this is "a survey" is highlighted $(180,194)$.

The Structure. The paper is based on readings related to autobiography theory and autobiographical writing, and it consequently explores the history of the term, the development of the genre in relation to other literary genres, reviewing over twenty sources all in all (listed in the Bibliography, 195-196). It highlights the critical observation about generic intersections and highlights the expansion of autobiography as a genre rooted in the humanities into the wider spectrum of life-writing which has been developing in the social sciences as well. The paper is therefore divided into five sections, each with a clear heading that refers to the discussed aspect. Hence the first section is entitled "The Development of Autobiographical Writing" which includes a review of several foundational sources in the history of autobiographical texts, inserting women's autobiographies within the tradition of autobiographical writing. Since writing autobiographies preceded autobiography theory, the paper starts with the writing, then moves in the second section to the theory as stated in the section heading "The Emergence of Autobiography Theorising" where the focus shifts from primary sources to secondary sources, that is to say from autobiographical texts to theoretical and critical texts. Having established autobiography as theory and practice, the paper then takes a turn and looks at this genre and literary tradition critically, identifying the blurred boundaries as emphasized in the third section of the paper given the heading "Autobiography: Generic Boundaries and 
Intersections." Here sources related to autobiography are reviewed clarifying the distinctions and interconnections between autobiography as such and other autobiographical genres such as memoirs, diaries, letters, relating them all to the recently emergent theory of Life-Writing. This leads to a review of the sources which discuss literary genres hybridised with autobiography, in the section entitled "Hybrid Genres: The Autobiographical Novel and Autofiction." The last section gathers all the strings together echoing the title itself in the section on "Current Trends in Autobiography Studies" thus ending with the latest contributions and the state of the art in autobiography theory.

The Discourse. Survey Papers are a genre of academic writing characterised by its discourse; namely the academic discourse which is generally known for being impersonal and persuasive in its attempts at conveying and convincing. In his discussion of the academic research discourse, Ken Hyland explains the main characteristics of the research discourse, explaining the notions of novelty and persuasion, which are evident in the literature review parts of a thesis or research article, where "writers construct a story for their study, persuading the reader that some organizing principle links their work into a coherent chain of disciplinary activity" $(2009,72)$. This applies even more evidently to the Survey Paper, where the writer interrupts the reviewing process to establish connections, to clarify the structure of the survey, and to prove its contribution to a specific discipline or field of knowledge. This can appear either in the introduction and/or conclusion, as well as in metatextual statements inserting at the beginnings or endings of the paper sections. In the case of "Trends in Autobiography Theory and Writing" this metatextual dimension is clear in the introductory part, the conclusion, and throughout the sections of the paper. It is however powerfully present in the Abstract where the structure of the paper is described, followed by a commentary on the paper as a whole in the following concluding sentence: "The paper marks the recent theoretical shifts in autobiography studies, and considers the future of both autobiography and life-writing in terms of both genre and critical inquiry" (Kamal 2020, 179).

\section{Conclusion}

As the title of this article shows, it is intended as a guide to direct young scholars towards the best practices related to publishable literature reviews. It is therefore grounded in the types and forms of theses, with particular reference to the case of the Faculty of Arts, Cairo University. Framed by the introduction and the conclusion, the paper is divided into four sections dealing with the types and 
forms of theses, the macrostructures of theses, the form and function of the literature review, and finally the process of transforming a literature review into a survey paper, using my elsewhere published survey paper as a case in point. In spite of this being a guide; that is to say neither a survey nor a research article, I have followed the conventions of academic writing. This guide/paper in that sense includes a clear methodology, a series of integrated literature reviews inserted into their relevant sections, as well as a concrete case study. The sources used in this study have themselves been categorised to fit their sections and to serve the aim and scope of this paper as a guide to emerging scholars, explaining the concept of a thesis, the location of a literature review, and its potential as an academic publication. Although specifically directed to the young researchers at Cairo University, this guide can be extended to serve several functions. 1) It explains the traditional, established, and innovative types and forms of theses and dissertations, thus enabling one to situate their own research within a selected frame. 2) It identifies the components of theses and dissertations, and explains their various macrostructures, thus providing scholars with an overview of research structures applicable not only to theses, but also to research articles, survey papers, and academic writing in general. 3) It focuses on literature reviews, offering a somewhat detailed description of the process of reading for, and actually writing, a literature review, without limiting it to publishable articles, but in relation to theses and research articles as well. 4) By relying on a concrete example and a published survey paper, this guide does not seek to limit the understanding of literature reviews to these models, but conversely hopes that they would invite further applicable examples and instigate new models.

\section{Works Cited}

Blair, Lorrie. 2016. Writing a Graduate Thesis or Dissertation. Rotterdam: Sense Publishers.

Felix, Mark Stephan, and Ian Smith. 2019. A Practical Guide to Dissertation and Thesis Writing. Newcastle-upon-Tyne, UK: Cambridge Scholars Publishing.

Galvan, Jose L., and Melisa C. Galvan. 2017. Writing Literature Reviews: A Guide for Students of the Social and Behavioral Sciences. New York and London: Routledge.

Hyland, Ken. 2009. Academic Discourse: English in a Global Context. London and New York: Continuum. 
Kamal, Hala. 2020. "Trends in Autobiography Theory and Writing." Philological Studies 33: 179-196. https://studiafilologiczne.ujk.edu.pl/gb/view/787

McMillan, Kathleen, and Jonathan Weyers. 2013. How to Research \& Write a Successful PhD. Harlow : Pearson Education UK.

Paltridge, Brian. 2002. "Thesis and Dissertation Writing: An Examination of Published Advice and Actual Practice." English for Specific Purposes 21: 125-143.

Paltridge, Brian, and Sue Starfield. 2020. Thesis and Dissertation Writing in a Second language: a Handbook for Supervisors. London: Routledge.

Sources in Arabic:

$$
\begin{aligned}
& \text { ترتيب عناصر الخطة لرسائل الماجستير الدكتور اه (المسار القديم). }
\end{aligned}
$$

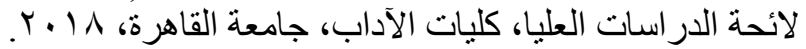

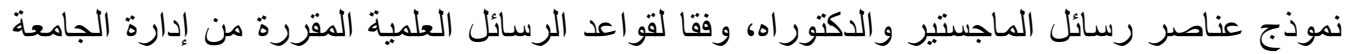

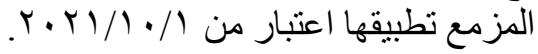

